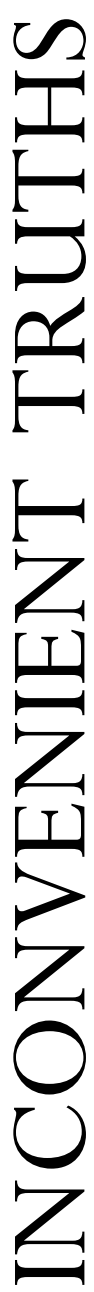

\section{Private practice-definitely not a zero sum game}

In a zero-sum game, one of the participants gains in proportion to the losses of the others. It is a widely held view that private medical practice thrives as (and perhaps because) the NHS declines. Is this correct?

May I start by declaring two conflicts of interest which actually conflict with one another? In 1975, as a final-year medical student, I was a member of MCAPP (The Medical Committee against Private Practice). We, the committed few, used to meet in basement flats in parts of London that then seemed rather dingy but are now almost certainly 'gentrified', highly desirable and most unlikely to be affordable by almost any medical practitioner. We plotted, and may have even conspired, to bring about the downfall of private medical practice. The Secretary of State for Health, Barbara Castle, was all for removing 'pay-beds' from NHS hospitals. Unlikely as it now sounds, the doctors (that is the $99.98 \%$ of the profession that did not belong to MCAPP) proved too powerful a lobby . . . the rest is history.

The second conflict relates to loss of virginity - and by that I mean the day I first saw a fee-paying patient as a (newly-appointed) consultant physician. A most distinguished colleague phoned me up (for younger readers, just imagine a time when doctors actually spoke to one another rather than sent an e-mail!) to ask me to see Sheikh someone or other. Rather feebly, I reiterated what I had emphasized at my job interview that what I said about wishing to focus entirely on developing the NHS service was true. Anyway I got to about sentence two, word three of my reply when the great man interjected to say he thought I was talking nonsense and, in any case, the patient was already in a taxi on his way to see me. How are the mightily principled fallen.

That violation was insufficient to change my perspective for several years but was sufficient to throw in doubts where I had always been sure. I had always assumed, almost as an act of faith, that those of my colleagues who were really into private practice in a serious way were there for the money. The problem for me was that, right from the start, it was professionally most rewarding to be able to see a newly-referred (three-day wait for an appointment) patient with altered bowel habit on a Monday, diagnose the colon cancer at colonoscopy on the Tuesday, get the biopsy and CT scan results on the Wednesday, and refer the (fully worked-up) patient for surgery within 48 hours of their first appointment.

The new NHS consultant contract is a godsend for those of us whose commitment to the NHS is total but the hours when we are asked to demonstrate that commitment are lengthy run, a swim, or maybe a private clinic. I worry about whether I can get a NHS patient referred with probable cancer through to starting treatment within 62 days. In private practice, I'm just as worried if I can't manage that within 62 hours.

Who loses? Not NHS patients, whose speed through the system has been enhanced not least by DoH targets set as a result of unfavourable comparisons with the private sector, as well as almost anywhere else outside the third world. Not private patients, who get the service they expect and pay for. Not the NHS, who gains by ensuring their consultants work to job plan, and (an old one this but no less true) have patient waiting times reduced by the private patients by-passing the system. And, yes, 'tis true. While I would wish my work to be its own reward, I am most reluctantly obliged as a professional to present a fee for my work. Truly, there are no losers.

\section{Ian Forgacs}

King's College Hospital, Denmark Hill, London SE5 9RS, UK (private practice address not the above and undisclosed)

E-mail: ian.forgacs@kcl.ac.uk

\section{Longer appointments for all!}

It seem bizarre that if we look at the way that a general practitioners' surgery is planned and organized in 2006, it is not very different from that which existed in 1948 at the creation of the NHS. It is true that the advent of information technology has had a profound impact on the exchange and recording of information but it has had little impact on the process of consultation between patient and doctor. There is a greater team of people working in primary care and patients are able to see and receive care from a greater range of professionals, but in terms of the doctor-patient interaction, much remains the same. In 1948, the average consultation time was five minutes. Until recently it was seven and a half minutes and it may be that it is now nearer ten minutes. Yet the complexity of problems that we deal with are far greater than they were in 1948. Access to investigation and treatments, the information that is presented for each individual consultation, the interventions that are available and the co-ordination of the care that is required are all much greater.

How can we possibly deal with it in the space of a seven and a half minute consultation?

The reality is that we do and we do it imperfectly. An eminent $\mathrm{GP}^{1}$ once boasted that in actual fact the GP consultation is nearer 47 minutes a year. This was based on the assumption that the average person consults their GP about five times a year for about nine minutes and the consultation is therefore part of an on-going conversation. This takes no account of the fact that the average person will see several GPs a year, albeit as part of the same practice. It seems an incredibly inefficient way to organize 
care, bringing the patient back five times so that we can complete our history taking, examination, investigation and management plan. From the patients' perspective it takes no account of the amount of time a patient may spend trying to get an appointment and waiting to be seen. The net result of our 1948 view of the consultation is that we have to keep seeing patients more regularly, creating a selfperpetuating demand for appointments that are never quite long enough. We seem to be fulfilling the negative comments about general practice made by a social commentator in 1912 as 'perfunctory work . . . of perfunctory men!'2 And all the time the mandarins tell us that we need to be seeing patients more quickly. You can't reconcile continuity with easy access - or, ultimately, patient satisfaction with short, sharp, ineffective appointments.

So here's an inconvenient truth. Why not introduce a right for patients to have a minimum 15 minute appointment with their GP? It should be a standard for the NHS just as much as clean wards, reduced waiting times for operations and free care at the point of delivery. Reinforce it by stating that GPs should see a maximum of 28 patients a day and see what happens. It will reduce the demand for appointments, improve satisfaction for both patient and doctor, and allow doctors to deliver the more advanced care that current knowledge requires - and so reduce the demands on the secondary care services.

Try it and see. All we have to fear is another sixty years of the same!

\section{Competing interests None declared.}

\section{Aneez Esmail}

E-mail: aneez.esmail@manchester.ac.uk

\section{REFERENCE}

1 Gray DP. The forty seven minute consultation. Br J Gen Pract 1998;48:1816-7

2 Allbutt C. The act and the future of medicine. Times 3 January 1912

\section{Poor handwriting remains a significant problem in medicine}

In centuries past, doctors scribbled notes to keep a personal record of the patient's medical history. The notes were generally seen only by the doctor. Today, doctors are no longer one-man bands. With dozens of other professionals, doctors are but one element of a large, multidisciplinary health care team. A consequence of this expansion is that illegible scrawls, hurriedly composed by rushed doctors, are now presented to colleagues with no qualifications in cryptology.

In a BMJ editorial in March 2000, Leape and Berwick called handwritten medical notes a 'dinosaur long overdue for extinction. ${ }^{1}$ Six and a half years on, the dinosaur is alive and well. In 2002, a report in this Journal revealed that 15\% of case histories were illegible. ${ }^{2}$ In 2005, three surgeons audited the legibility of 40 randomly selected operative notes from an orthopaedic ward in a large British hospital. ${ }^{3}$ Two nurses, two physiotherapists and two medical house officers were asked to rate the legibility of the notes as 'excellent', 'good', 'fair', or 'poor'. Only 24\% were rated 'excellent' or 'good', and 37\% were deemed 'poor'.

For members of the health care team, deciphering the notes can be a nuisance, sometimes requiring the assistance of colleagues and, if a signature is present and legible, a direct call to the author. Often, no name is left on the form. ${ }^{4}$ The considerable time and frustration associated with this detective work far outweighs the extra effort needed to dot an ' $i$ ' or cross a ' $t$ '. Trying to save time by writing quickly is thus a false economy.

From the patient's perspective, illegible handwriting can delay treatment and lead to unnecessary tests and inappropriate doses which, in turn, can result in discomfort and death. In 1999, an American cardiologist caused the death of a 42-year-old patient when his prescription of 20 $\mathrm{mg}$ Isordil, an antianginal drug, was misread by the pharmacist as $20 \mathrm{mg}$ Plendil, an antihypertensive drug. ${ }^{5}$ Poor handwriting undoubtedly contributes to another inconvenient truth: the high incidence of medical errors in Britain, which is estimated to cause the deaths of up to 30000 people each year. ${ }^{6}$

Illegible handwriting in medical records can have adverse medico-legal implications. Stephens notes that 'few admissions look more damaging in testimony than physicians admitting they cannot read their own handwriting. Sloppy handwriting can be interpreted by the jury as sloppy care'. ${ }^{7}$ In the Medical Defence Union's Ten Commandments of record keeping, 'Thou shalt write legibly' comes top of the list. ${ }^{8}$ So, how best to fix this problem? A sophisticated IT system to computerize patient notes? Handwriting tests as part of hospital appointments? Penmanship classes for medical staff, like those conducted in some North American hospitals? ${ }^{9}$ After careful reflection, we propose a less daunting and more economical solution for the graphologically challenged: a New Year's resolution to write more legibly. This commitment must be made, of course, in writing.

\section{Competing interests None declared.}

\section{Guarantor Daniel Sokol.}

\section{Daniel K Sokol ${ }^{1}$ and Samantha Hettige ${ }^{2}$}

${ }^{1}$ Centre for Professional Ethics, Keele Hall, Keele University, Staffordshire ST5 5BG, UK

E-mail: daniel.sokol@talk21.com

${ }^{2}$ St George's Hospital, Tooting, London, UK 


\section{REFERENCES}

1 Leape L, Berwick D. Safe health care: are we up to it? BMJ 2000;320:725-6

2 Rodriguez-Vera F, Marin Y, Sanchez A, Borrachero C, Pujol E. Illegible handwriting in medical records. $J$ R Soc Med 2002;95:545-6

3 Gakhar H, Sawant N, Pozo J. Audit of the legibility of operation notes. In: Royal College of Surgeons of Edinburgh Audit Symposium 2005. Edinburgh: RCS Ed, 2005

4 Thompson A, Jacob K, Fulton J. Anonymized dysgraphia. J R Soc Med 2003;96:51

5 Charatan F. Family compensated for death after illegible prescription. BMJ 1999;319:1456

6 Medical errors 'kill thousands'. BBC News Online. 2000. Available at http://news.bbc.co.uk/1/hi/uk/682000.stm (accessed 14 October 2006)

7 Stephens E. Medical-legal liability in emergency medicine. 2005. Available at http://www.emedicine.com/EMERG/topic945.htm (accessed 14 October 2006)

8 Norwell $\mathrm{N}$. The ten commandments of record keeping. JMDU 1997; 13:8-9

9 'Handwriting challenged' doctors to take penmanship class at Cedars-Sinai Medical Center. 2000. Available at http:// www.sciencedaily.com/releases / 2000/04/000426155803.htm (accessed 14 October 2006)

\section{Fear ever young: the terrorist death toll in perspective}

Why are people not afraid of driving? There are plenty of people afraid of flying, and the terrorist attacks of $2001 \mathrm{can}$ only have exacerbated this phobia. Whenever you board a plane you can see them: anxious passengers gripping their boarding passes so hard they jam the automated counters at the boarding gates. Where are the masses sweating and shaking with fear as they climb into their cars?

Clearly fear is not always founded in facts. Every year over one million people around the world die in road traffic accidents, compared with about one thousand deaths from plane crashes. The difference is that every fatal plane crash makes the news whereas most car accidents remain

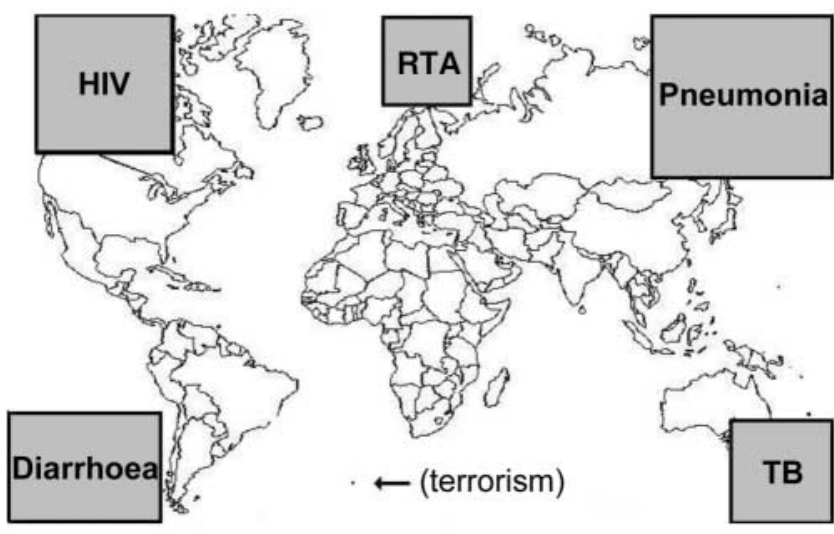

Figure 1 Relative magnitude of global deaths in 2001 from selected causes. Data taken from the WHO World Health Report, 2002. traffic accidents, TB, Tuberculosis anonymous. In their safety briefings, flight attendants never warn you that you are sixty times more likely to die driving home from the airport than during the flight. ${ }^{1}$

This bias in reporting deaths also applies to terrorism. One individual taken hostage and murdered by some extremist group makes news headlines worldwide. If the BBC World Service tried to report each AIDS death for one year, the broadcast would take more than a year to deliver - even without interruption and allowing just 10 seconds per death. If we considered tobacco-related deaths, even two simultaneous news bulletins couldn't keep up with the death toll.

Everyone remembers where they were when those planes crashed into the World Trade Center killing three thousand innocent victims on 11 September 2001. It changed human history. But how many people know that on the same day five years ago, more than four thousand children died of diarrhoea, three thousand people died in car accidents, and eight thousand died of AIDS?² In 2003 the collective annualized mortality burden from tobacco was more than five thousand times that of terrorism. ${ }^{3}$ Furthermore, these deaths continued unabated on 12, 13 and 14 September, and every day since. The even greater tragedy is that they were preventable. Despite the billions being spent on 'the war on terror', are we any safer?

There is no question that terrorism is a global problem that needs to be addressed. However, as Jeffrey Sachs explains, 'We need to keep September 11 in perspective, especially because the ten thousand daily deaths (from AIDS, TB, and malaria) are preventable. ${ }^{3}$

Competing interests The author holds a pilot's licence.

\section{Hasantha Gunasekera}

\section{REFERENCES}

1 National Safety Council. What are the odds of dying? Available at http:// www.nsc.org/lrs/statinfo/odds.htm (accessed 15 October 2006)

2 WHO. World Health Report, 2002. Available at http://www.who.int/ whr/2002/en/whr02_annex_en.pdf (accessed 15 October 2006)

3 Thomson G, Wilson N. Policy lessons from comparing mortality from two global forces: international terrorism and tobacco. Global Health 2005; $1: 18$

4 Sachs J. The End Of Poverty. How We Can Make It Happen In Our Lifetime. London: Penguin, 2005:215

\section{Too little compassion in health care?}

I have been visiting one of England's major teaching hospitals a couple of times every week for most of this year. My father in law is a 'frequent flier' with heart failure and various comorbidities. Seeing the NHS through the lens of his care is sobering. The NHS's addiction to structural change as a way of sorting things out seems unlikely to shift his shoddy 
support. This obsession with moving the resources around seems to know no bounds and yet is useless for him.

In the media we see continued coverage about sacking unaffordable staff this year and senior NHS and DoH leaders encouraging the closure of hospitals in the tail end of this decade. Others offer rationing services and big projects (like the national IT programme) as the only routes to sustainability. From my experience these are pretty irrelevant - what is really needed is a fundamental shift in how people relate to each other: staff to staff, patients to staff. And this is measured in the small things: the nurse who phones social services (again) to try to get a completed and accurate assessment $~-n o t$ the nurse who refused to go to the hospital shop to buy the barriernursed patient a bottle of orange squash.

If everyone who works in NHS did one extra act of kindness a day (the GP on a home visit who boils that egg for a housebound patient, the consultant who buys a phone card for a bed-bound patient and helps them to use it) and took one extra step to make things join up better for a patient (the SHO who phones the GP, the ward clerk who talks to the $\mathrm{X}$ ray department, the sister who phones the relatives to brief them on a change in regime), the whole system would take a massive step forward in terms of service and smoothness, and would seem simpler to patients and more satisfying for staff. Once the NHS shifts out of its chaotic turbulence it is possible to try other improvements. Structural change is a side alley en route to giving patients and carers greater and greater value from the skills of staff. Process improvements with IT are only part of the answer. Changing the way that compassion is shown, kindness demonstrated, conflict is handled and decisions managed would be totally transforming. Starting with the little things is critical. It doesn't need a government policy or mandate from the top. This is a strategy that everyone can create - and all can implement.

\section{Competing interests None declared}

Dedication This piece is dedicated to Jane on F4, who took a step and changed it all.

\section{Phil Hadridge}

iDENK Ltd.

E-mail: phil.hadridge@idenk.com

\section{Where has the humanity gone?}

The really inconvenient truth in the world of healthcare and medicine will never go away: it's run by people, for people, and 'there's nowt queer as folk.'

Throw our less appealing human tendencies (in part summed up as reluctance or inability to imagine how life might be for others) into a melting pot with professional bureaucratic strangleholds and patients who don't feel great, and what better recipe for trouble?
Some fantastic doctors give good care in a tough climate, some assiduous managers try to ensure what they offer is properly run and allocated. And we're inconveniently imperfect patients. Those 20 million appointments every year we don't attend or cancel, those healthy diets and exercise programs we don't follow, our reluctance to accept the reality of limited resources. Sure, the system can and does let us down appallingly at times, but we too need to admit that, however much we want to see the doctor, and now, to get some treatment we saw on the internet, (a) there may be someone more ill who must go first, and (b) they need an expensive life-saving drug more than we need asparagus suppositories.

While recent research reveals that patients think they're lucky (albeit unusual) in having good dealings with the NHS (Lost in Translation, NHS Confederation, 2006), a couple of years ago, combining an NHS post with journalism and interviewing countless professionals and patients, I kept hearing the same question: where has the humanity gone?

Patients were at a loss, professionals cited bureaucratic burdens. I wrote a book about the mess, rolling the words of many real doctors into a fictional one, who says: 'Pointless tasks, meetings, counting games. You can give me an abacus, but I can't promise you sweeter medicine.'

Surely-and we need to ask this, for want of an evidence-base that mushrooming management gives us a better time if we get sick - sweeter medicine is about that extra ounce of humanity? And finding it, even when, as a doctor, you've just had a row about targets, budgets and how much red tape you need to wrap it up in. Or when, as a patient, you feel dreadful and the system's apparently conspiring to make it worse.

While it is naive to suggest curing the NHS's ills by being nicer to each other, it's surely part of the picture, and it keeps getting buried under rarefied rows. We need to work together, hard and fast, to claw back tender, loving health care before losing sight of what it is. Getting better is about people, not about politics, professional posturing and pride. Well or ill, we're in this together. Counting games may be a necessary part of the picture, but so too is stepping back, little and often, and asking whether we're treating each other well. Some days, that feels like the last achievable thing on earth. Surely it always has to be the first?

Competing interests These views do not necessarily reflect those of the AMRC.

\section{Sophie Petit-Zeman}

Association of Medical Research Charities, 61 Gray's Inn Road, London WC1X 8TL, UK

E-mail: s.petit-zeman@amrc.org.uk 


\section{Reasons to be cheerful (times three)}

Why are doctors so bloody miserable nowadays? Whingeing medics spout their complaints all over the media. A Martian trying to understand how the NHS worked by reading Hospital Doctor would assume it was a derivative of Stalin's Gulag Archipelago. And hospital corridor gossip is dominated by dissatisfaction.

There are a limited range of perceived culpritspoliticians, managers, the $\mathrm{MMC}$ - and an even more limited range of solutions - more power and/or money for doctors, and privatizing the NHS either faster or slower than the current government.

All of which is very strange when we consider the power of modern medicine to diagnose and treat illness. We are privileged to live in the era that medicine finally delivered in bulk what its proponents had been falsely claiming for centuries: accurate diagnosis and effective treatments. It is the huge successes of modern medicine that are the principal cause of the many real problems that do afflict our working lives, and we should be aware that these problems are often the inevitable consequence of good things.

First, we are now trying to ensure everyone who might benefit receives appropriate health care. Even 20 years ago, a lot of modern medical care was not available to the old, the disabled, those with other illnesses or even just those whose local hospital wasn't a teaching hospital. The increase in work has been enormous and it is hardly surprising that our resources are often thinly spread. And remember that the struggle for resources for expensive new investigations and treatments is not just an NHS problem; it exists in every modern health care system. I don't like working in an understaffed, cramped facility, but it always was and always will be a fight to win the case for more staff and better equipment.

Second, the age of deference is over. The NHS is not a charity, and patients are not automatically grateful for whatever treatment we deign to offer. It takes time to help patients understand what is happening to them, and to explain their options and our preferences. It takes time to explain why they need to keep taking their tablets despite what it said about them in the paper or on the net. And it takes time to establish a healthy rapport - a vital aspect in the age of powerful but dangerous treatments. It's quite handy for your patients to have a chance to develop some trust in you before you put them through whatever ghastly ordeals are needed to fix them. We don't need to be perceived as superheroes, we need to be perceived as normal human beings with special training doing the best we can in sometimes impossible circumstances.

Finally, and least importantly: the pay is very good indeed. Don't compare with fat cat executives or heart surgeons with a big private practice, compare with your patients or any of the other members of your team, or even with what you were making before the new contract came in. And remember we get that generous wage for improving health and prolonging life in ways never imagined by all of our predecessors over the last two thousand years. This is about as good as it gets, and it's not bad. Get some perspective, and stop moaning.

Competing interests None declared.

John Main

E-mail: John.Main@stees.nhs.uk 